decided red colour, the rest being white, as usual. Taking up some that fell in the gig, Mr. Mullan found that the colour was not merely superficial, but pervaded the substance of the hailstone, and, on melting, they stained the fingers. He did not think, or had not the means, of preserving any of the water resulting. Has the like been observed before?

\section{Spectral Images}

Mr. BIDWELL's notice of spectral images (NATURE, vol. xxxii. p. 30) calls to mind certain phenomena I witnessed while riding in a railway train in Kentucky last October. The fence of the railway consisted of posts of about 6 inches in diameter, and twenty paces apart, connected by wires. The posts had newly been painted green. I was seated on the right side of the carriage, face forwards; the speed fully twenty miles an hour, with the sun behind my right shoulder, when looking at the posts on the left side, brightly illuminated by the sun, I observed that each post had the appearance of a twin post immediately in advance of it-touching it-of a red colour. To make myself sure that I was not deceived by some abnormal affection, I called the attention of a niece of mine to the phenomenon, and she saw it quite as well as I did. Another niece, however, failed to make it out. I am under the belief that the red post was the complementary colour of the green one, appearing the instant after the latter had been seen, and though apparently in advance in space of the green pust, really was seen later in time. The fact of both being apparently seen simultaneously, is accounted for by the well-known law of retinal images lingering on vision.

HeNRy Mutrhead

Cambuslang

\section{THE NEW OUTBURST OF LAVA FROM VESUVIUS}

YESTERDAY, May 2, up to two o'clock, Vesuvius appeared to be in its natural state of activity, such as persisted with slight variations for some considerable time. At that hour the lava, which was at some height within the cone of eruption, forced a way out at its base, traversing the plain of old lava filling the crater of 1872 , and producing a rent about one quarter the way down the great Vesuvian cone. This rent represents the extension outwards of a volcanic dyke that has been in process of formation for over two years. A visitor during that period who walked around the southern rim of the 1872 crater, might have noticed a fissure varying from a few inches up to 2 feet wide, and extending inwards across the crater plain, until lost beneath the ejectamenta of the cone of eruption. From this fissure issued a powerful current of hot air, and in part of its course an abundance of $\mathrm{HCl}$. This latter was indicated by the continual decomposition of the scoria and ash in its immediate neighbourhood, so that a large patch of yellow dust filled with the unattached pyroxene crystals was a point of bright colour in the black scoria-covered lava-plain. The lava at first actually issued, or, more properly, welled up from this fissure, but its point of exit was soon lowered by the cutting down of the outer slope. The lava soon commenced to flow down the cone with considerable rapidity, forming two distinct parallel streams averaging fifty metres apart, so that in the evening the landscape was lit up by these two brilliant streaks of fire. This morning I started early, and ascended on foot to the eastem side of the two streams, though often inconvenienced by the hot wind and exhalations blown off the lava. The streams take origin close together, and no doubt conjoin, but are covered by scoria-a vast quantity of lapillo and ash that has been slipped downwards and forward, forming a rough annular space which would require a drawing to explain. At the upper end of this we have part of the great cone slipped down, showing in section the dyke, which I may call hollow; we have a fissure which was filled by lava, and which consolidated and adhered to its sides, forming salbam; but before the central part solidified, the general level was lowered, and it drained away, leaving the dyke divided in two by an empty space. At 2 p.m. to-day the streams of lava had the following dimensions at their exit :-

$$
\begin{array}{ccc}
\text { Eastern } & \text { Western } \\
\text { Breadth about } I \frac{1}{2} \text { metres } & \ldots & \text { About } 2 \frac{1}{2} \text { metres } \\
\text { Depth estimated at I metre } & \ldots & \text { at } 2 \text { metres } \\
\text { Rate of flow on both, about } I \text { metre per second. }
\end{array}
$$

The output therefore equals for the eastern stream about 90 cubic metres per hour, or 2160 cubic metres in 24 hours, whilst that of the western stream represents 300 cubic metres per hour, or 7200 in 24 hours. The two streams, therefore, represent an output of 9360 cubic metres during the 24 hours, from May 2 to 3 , at 2 p.m. This quantity would equal a deposit of rock of about I $\mathrm{km}$. long, $9 \mathrm{~m}$. broad, and I $\mathrm{m}$. thick, which is rather an under-estimation of what now lies on the side of the mountain, for the two streams had at the hour of observation traversed more than two-thirds of the pedimenture. The amount of lava represents far more than what occupied the chimney above the level of the lateral opening, and the mechanism of the increased quantity extruded I have gone into fully in a paper read last week before the Geological Society. The cone of eruption only now gives forth vapour, its stone-throwing propensities being stopped by the lowering of the magma level. In consequence of the want of support of its inner walls by disappearance of the fluid column, these are rapidly crumbling in, and the craterial inner cavity much increased in size. In the same way a breach has been made in the line of the dyke by falling in of that part of loose materials immediately above it.

This change in Vesuvius will no doubt be put down in history as an eruption, and possibly a relationship sought between contemporaneous earthquakes, or some other phenomena. It is nothing more nor less than the final giving way of part of the cone before a dyke that has been working its way out for years.

I send you these few notes after a long day's climb, exposed to great changes of temperature and mephitic vapours. I ask, therefore, that this will be taken as an excuse for these rough and ready notes, which I thought your readers would be interested to have quickly.
Naples, May 3
H. J. JOHNSTON-LAVIS

\section{EXPERIMENTS WITH COAL-DUST AT NEUNKIRCHEN, IN GERMANY}

$\mathrm{I}$ a former article on this subject which appeared in NATURE of Nov. 6 last (p. I2), I described the apparatus employed by the Prussian Firedamp Commission in making their experiments, and at the same time I gave an account of four experiments that were seen by $\mathrm{Mr}$. $\mathrm{Wm}$. Thomas Lewis and myself.

No official account of these experiments had been published at that time, but quite recently Herr Hilt and Herr Margraf have made a joint report in the name of the Commission. As this report is intended to be only a preliminary one, it does not give the whole of the details of each experiment, but it shows as far as it goes that everything has been conceived and carried out in a spirit of liberality and thoroughness.

At the outset Herr Hilt states that the uncertainty which seemed to surround this important question, and in particular the peculiar views that had been enunciated by MM. Mallard and Le Chatelier, who reported upon it to the French Commission du Grisou, ${ }^{3}$ had induced him to address a letter on the subject, dated December I5, I883, to the Prussian Welter-Commission, urging them as a matter of duty to take it up and investigate it by a series of large-scale cxperiments. The French Commissioners, referred to, stated at the end of their report that " they considered it established that coal-dust in the absence of fire-damp does not constitute an element of

$$
\text { 'Annales des Mines, Janvier-F́́vrier, I88a. }
$$

